\title{
ACCURACY OF DECIDUOUS AND PERMANENT MOLAR TEETH IN GENDER DETERMINATION OF EGYPTIAN CHILDREN: DENTAL AND FORENSIC IMPLICATIONS
}

\author{
Ahmed Ibrahim El Dosoky*, Fatma M. Elgazzar ** and Sara Abdel Aziz Gonna***
}

\begin{abstract}
Forensic odontology is an investigative aspect of dentistry that apply dental knowledge for legal issues including identification of unknown human bodies or remains. Sexual dimorphism of permanent teeth measurements has been extensively studied but, no studies involved pediatric age group with mixed deciduous and permanent dentition. The aim of this study was to determine accuracy of maxillary and mandibular deciduous and permanent molar teeth in sex determination in a sample of Egyptian children. Additionally, to estimate crown size of mandibular permanent first molar from mandibular deciduous second molar. A sample of 210 male and female children aged 6-12-years, in mixed dentition stage. Mesio-distal (MD) crown diameters of maxillary and mandibular permanent first molars and deciduous second molars were measured by a digital caliper. The mean MD crown diameter of both Rt maxillary and mandibular permanent first molars was significantly higher in males than females $(10.29 \pm .31$ vs $10.00 \pm .60$ and $11.01 \pm .51$ vs $10.71 \pm .60$ respectively, $\mathrm{p}<0.001)$. Furthermore, Rt and Lt mandibular deciduous second molars exhibited

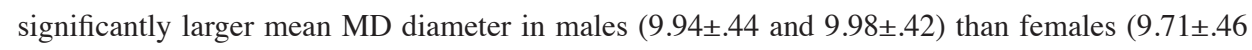
and9.74 \pm .46). Further, Simple linear regression revealed new equations for prediction of crown size of mandibular Rt permanent first molar from mandibular Rt deciduous second molar. Odontometric study of deciduous and permanent molar teeth showed poor accuracy in sex determination. They can be used in conjunction with other traits to establish gender accurately. Furthermore, this work presented new equations that will be helpful in estimating crown size of mandibular permanent first molar from mandibular deciduous second molar.
\end{abstract}

KEYWORDS: Odontometric, crown size, gender determination

\section{INTRODUCTION}

Forensic odontology is an investigative aspect of dentistry that apply dental knowledge for legal issues including identification of unknown human bodies or remains ${ }^{(1)}$. Teeth are the hardest structure of the human body. Teeth morphology and measurements are reliable methods of sex determination; as they

\footnotetext{
* Lecturer at Pediatric Dentistry, Oral Health and Preventive Department, Tanta University, Egypt

** Assistant Professor of Forensic Medicine and Clinical Toxicology, Faculty of Medicine, Tanta University, Egypt

*** Lecturer at Pediatric Dentistry Department, Tanta University, Egypt
} 
resist environmental changes, fire, and postmortem decomposition ${ }^{(2)}$. Additionally, the fact that most teeth complete development before skeletal maturation makes them a valuable sex indicator particularly in young individuals ( $^{(3)}$

Many studies from various countries and diverse populations have revealed sexual dimorphism of permanent teeth measurements- ${ }^{(4-8)}$. Alternatively, few studies involved deciduous dentition in pediatric groups of Spanish, European, south Indian, and Portuguese populations, with inconsistent accuracy $^{(9-12)}$.

It has been reported that morphometric traits of deciduous dentition have not well defined yet before puberty ${ }^{(11)}$. Furthermore, no studies involved pediatric age group with mixed deciduous and permanent dentition.

The mesiodistal crown width and occlusion in the deciduous dentition play a significant role in determining space and occlusion in the permanent dentition. One of the most critical factors in dental arch development and the relation of the arches to one another is mesiodistal diameter of the tooth ${ }^{(13)}$.

The aim of this study was to determine accuracy of maxillary and mandibular deciduous and permanent molar teeth in sex determination in a sample of Egyptian children. Additionally, to estimate crown size of mandibular permanent first molar from mandibular deciduous second molar.

\section{SUBJECTS AND METHODS}

\section{Study design, setting, ethical considerations:}

In this cross-sectional study, a random sample of children attended included the outpatient clinic of Pedodontics Departments, Faculty of Dentistry, Tanta University was recruited. This was done after approval from the local research ethics committee and taking a written informed consent from their parents or guardians. Confidentiality of data was maintained by coding all participants individually.

\section{Eligibility criteria:}

\section{Inclusion criteria}

Male and female children aged 6-12-years, in mixed dentition stage; in whom the maxillary and mandibular four permanent incisors and first molars bilaterally were completely erupted. Further, the deciduous second molars had not been replaced by the second permanent premolars. Additionally, normal molar relationship, absence of any skeletal discrepancies, and healthy state of periodontium were important prerequisites.

\section{Exclusion criteria}

Children had dental caries or lost dental material for any reason, abnormalities in size, shape, or structure of the teeth, proximal fillings or prosthetic restorations, beside any general medical condition or syndrome were excluded. Furthermore, children with history of previous orthodontic treatment or prolonged thumb sucking habits extended beyond 4 years of age (assessed by clinical history and intraoral occlusal examination) were also excluded.

\section{Sample size:}

Sample size was calculated with G*Power software program version 3.1. An effect size of 0.39 representing the assumed gender related difference between the mean deciduous second molars was chosen according to ${ }^{(12)}$, with an alpha level of 0.05 , a target power of $80 \%$, and male to female allocation ratio 1:1. The required sample size was found to be 210 .

\section{Methods:}

For every participant, alginate impressions were taken in suitable perforated trays for upper and lower arches and immediately poured with dental plaster stone to avoid any dimensional changes. The dental cast was allowed to dry on the table for one hour. Impressions were remade if flaws were found. A set of both maxillary and mandibular study models for each child was numbered for easy recognition ${ }^{(14)}$. 
Mesio-distal (MD) crown diameters of maxillary and mandibular permanent first molars and deciduous second molars ${ }^{(15)}$. This was taken using a digital caliper with an accuracy $0.01 \mathrm{~m}$.

It is the largest mesial-to-distal dimension, taken parallel to the occlusal surface. The caliper beaks were inserted from the facial aspect of the tooth and held perpendicular to the long axis of the same tooth (Fig1).

A random sample of thirty casts were remeasured after 2 weeks by the same observer to calculate intra-observer error. Furthermore, another observer examined the thirty casts to assess the inter-observer reliability.

\section{Statistics:}

The obtained data were tabulated and analyzed statistically using SPSS (Statistical Package for the Social Sciences), IBM SPSS Statistics for Windows, Version 22.0. Armonk, NY: IBM Corp.). Normality assumption was tested by Shapiro-Wilk test. They were normally distributed and were compared by Independent $T$-test. Additionally, diagnostic performance in discriminating gender was tested by receiver operating characteristics (ROC) curve analysis. A stepwise multiple binary logistic regression analysis was performed to explore a prediction model for male gender from the studied measurements that showed significant differences between both genders. As well, simple linear regression analysis was done to estimate crown size of mandibular permanent first molar from mandibular deciduous second molar. $P<0.05$ was considered statistically significant.

\section{RESULTS}

The study included 210 children of both genders (105 each), aged 6 to 12-years old. The mean age for males and females was $9.4 \pm 0.6$ and $9.7 \pm 0.6$ respectively with no significant difference. There was no statistically significant intra- or interobserver differences $(p>0.05)$. Additionally, the correlation coefficient of intrarater and interrater reliability was excellent (0.96).

The mean MD crown diameter of both Rt maxillary and mandibular permanent first molars was significantly higher in males than females (10.29 \pm .31 vs $10.00 \pm .60$ and $11.01 \pm .51$ vs $10.71 \pm .60$ respectively, $\mathrm{p}<0.001)$. Furthermore, $\mathrm{Rt}$ and $\mathrm{Lt}$ mandibular deciduous second molars exhibited significantly larger mean MD diameter in males $(9.94 \pm .44$ and $9.98 \pm .42)$ than females $(9.71 \pm .46$ and9.74 \pm .46$)$ as demonstrated in table (1).

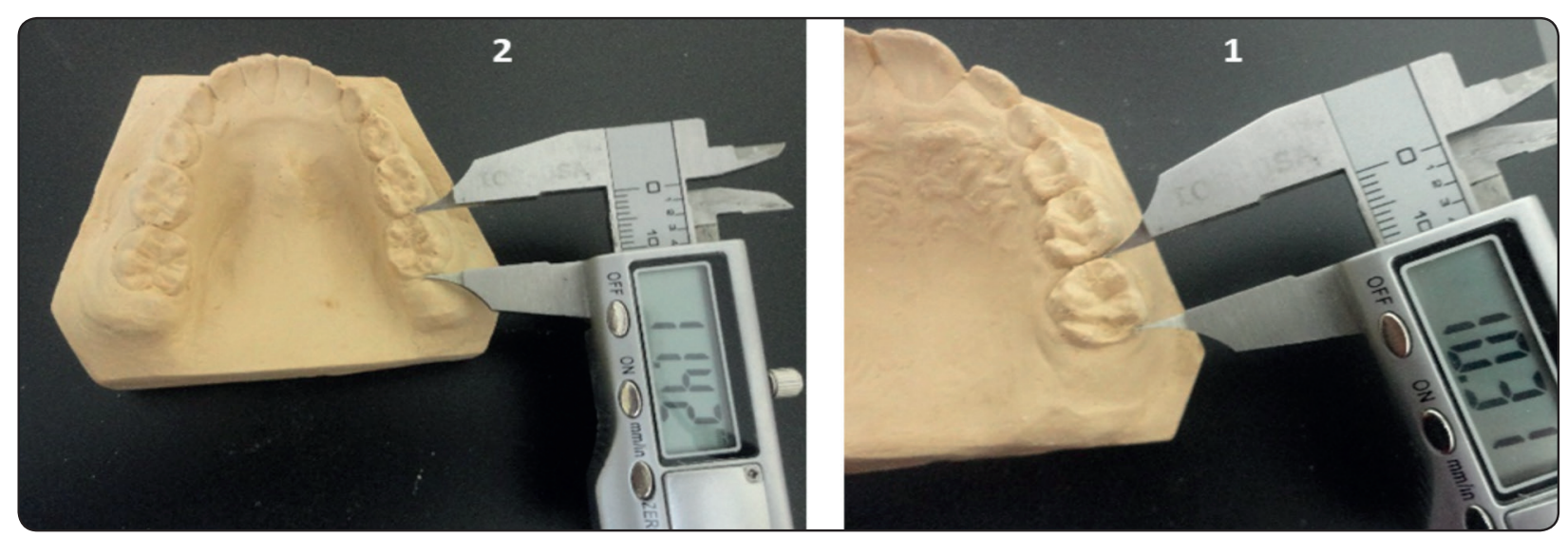

Fig. (1): Measurement of mesio-distal crown diameter (mm) of maxillary (1) and mandibular (2) permanent first molars by a digital caliper. 
TABLE (1): Comparison between males and females regarding mesiodistal crown diameter of the studied teeth $(\mathrm{N}=210)$.

\begin{tabular}{|c|c|c|c|c|c|}
\hline \multirow{2}{*}{\multicolumn{2}{|c|}{ Mesiodistal crown diameter (mm) }} & \multicolumn{2}{|c|}{ Groups } & \multicolumn{2}{|c|}{ Independent $\mathrm{T}$ test } \\
\hline & & \multirow{2}{*}{$\begin{array}{c}\text { Males } \\
\mathrm{N}=105\end{array}$} & \multirow{2}{*}{$\begin{array}{c}\begin{array}{c}\text { Females } \\
\mathrm{N}=105\end{array} \\
10.00 \pm .60\end{array}$} & \multirow{2}{*}{$\frac{t}{4.35}$} & \multirow{2}{*}{$\begin{array}{l}\text { P value } \\
<0.001 *\end{array}$} \\
\hline Maxillary Rt permanent first molar & Mean \pm SD & & & & \\
\hline Maxillary Lt permanent first molar & Mean \pm SD & $10.13 \pm .42$ & $10.00 \pm .60$ & 1.81 & 0.071 \\
\hline Maxillary Rt deciduous second molar & Mean \pm SD & $8.56 \pm .42$ & $8.47 \pm .52$ & 1.34 & 0.179 \\
\hline Maxillary Lt deciduous second molar & Mean \pm SD & $8.53 \pm .42$ & $8.43 \pm .51$ & 1.64 & 0.102 \\
\hline Mandibular Rt permanent first molar & Mean \pm SD & $11.01 \pm .51$ & $10.71 \pm .60$ & 3.81 & $<0.001 *$ \\
\hline Mandibular Lt permanent first molar & Mean \pm SD & $10.82 \pm .52$ & $10.70 \pm .56$ & 1.59 & 0.112 \\
\hline Mandibular Rt deciduous second molar & Mean \pm SD & $9.94 \pm .44$ & $9.71 \pm .46$ & 3.68 & $<0.001 *$ \\
\hline Mandibular Lt deciduous second molar & Mean \pm SD & $9.98 \pm .42$ & $9.74 \pm .46$ & 3.87 & $<0.001 *$ \\
\hline
\end{tabular}

*Significant at $p<0.05$

ROC curve analysis of the above measurements revealed significant but poor performance in discriminating males from females (AUCs ranged from 0.63 to $0.65, \mathrm{p}<0.05)$. No significant differences were observed regarding their power of discrimination ( $\mathrm{p}>0.05)$, but maxillary Rt permanent first molar showed the greatest accuracy $(67.50 \%)$ in classifying male gender, besides $100 \%$ diagnostic sensitivity and NPV at a cut off $>9.74 \mathrm{~mm}$ (Table 2 and Fig 2).
Stepwise multiple binary logistic regression analysis revealed a model consisted of MD diameter of maxillary and mandibular Rt permanent first molar, and mandibular Rt deciduous molar. The model contributed significantly for determining male gender $\left(\mathrm{X}^{2}=32.64, \mathrm{p}<0.001\right)$. The model had good power in discriminating male gender $(\mathrm{AUC}=0.718)$, and the accuracy of confirming male gender was $69.50 \%$. Maxillary Rt permanent first molar exhibited the largest (3.08) odds ratio Table (3).

TABLE (2): Receiver operating characteristics (ROC) curve analysis for prediction of male gender.

\begin{tabular}{|l|c|c|c|c|c|c|c|c|c|}
\hline & Cut off & $\begin{array}{c}\text { Sensitivity } \\
\%\end{array}$ & $\begin{array}{c}\text { Specificity } \\
\%\end{array}$ & $\begin{array}{c}\text { PPV } \\
\mathbf{\%}\end{array}$ & $\begin{array}{c}\text { NPV } \\
\mathbf{\%}\end{array}$ & AUC & $\mathbf{9 5 \%}$ CI & $\begin{array}{c}\text { Accuracy } \\
\%\end{array}$ & P value \\
\hline $\begin{array}{l}\text { Maxillary Rt permanent } \\
\text { first molar }\end{array}$ & $>9.74$ & 100.0 & 35.24 & 60.61 & 100 & 0.63 & $\begin{array}{c}0.56 \text { to } \\
0.69\end{array}$ & 67.50 & $0.011^{*}$ \\
\hline $\begin{array}{l}\text { Mandibular Rt permanent } \\
\text { first molar }\end{array}$ & $>10.81$ & 68.57 & 60.0 & 63.30 & 65.93 & 0.65 & $\begin{array}{c}0.59 \text { to } \\
0.72\end{array}$ & 64.50 & $0.001^{*}$ \\
\hline $\begin{array}{l}\text { Mandibular Rt deciduous } \\
\text { second molar }\end{array}$ & $>9.85$ & 62.86 & 63.81 & 63.64 & 63.37 & 0.64 & $\begin{array}{c}0.57 \text { to } \\
0.70\end{array}$ & 63.50 & $0.001^{*}$ \\
\hline $\begin{array}{l}\text { Mandibular Lt deciduous } \\
\text { second molar }\end{array}$ & $>9.75$ & 72.38 & 58.10 & 63.16 & 67.44 & 0.65 & $\begin{array}{c}0.58 \text { to } \\
0.712\end{array}$ & 65.0 & $0.001^{*}$ \\
\hline
\end{tabular}

Pairwise comparison of AUCs of palatal length, width, and height revealed nonsignificant differences (p>0.05)

*Significant at $p<0.05$. AUC: area under the curve, PPV: positive predictive value, NPV: negative predictive value, CI: confidence interval 


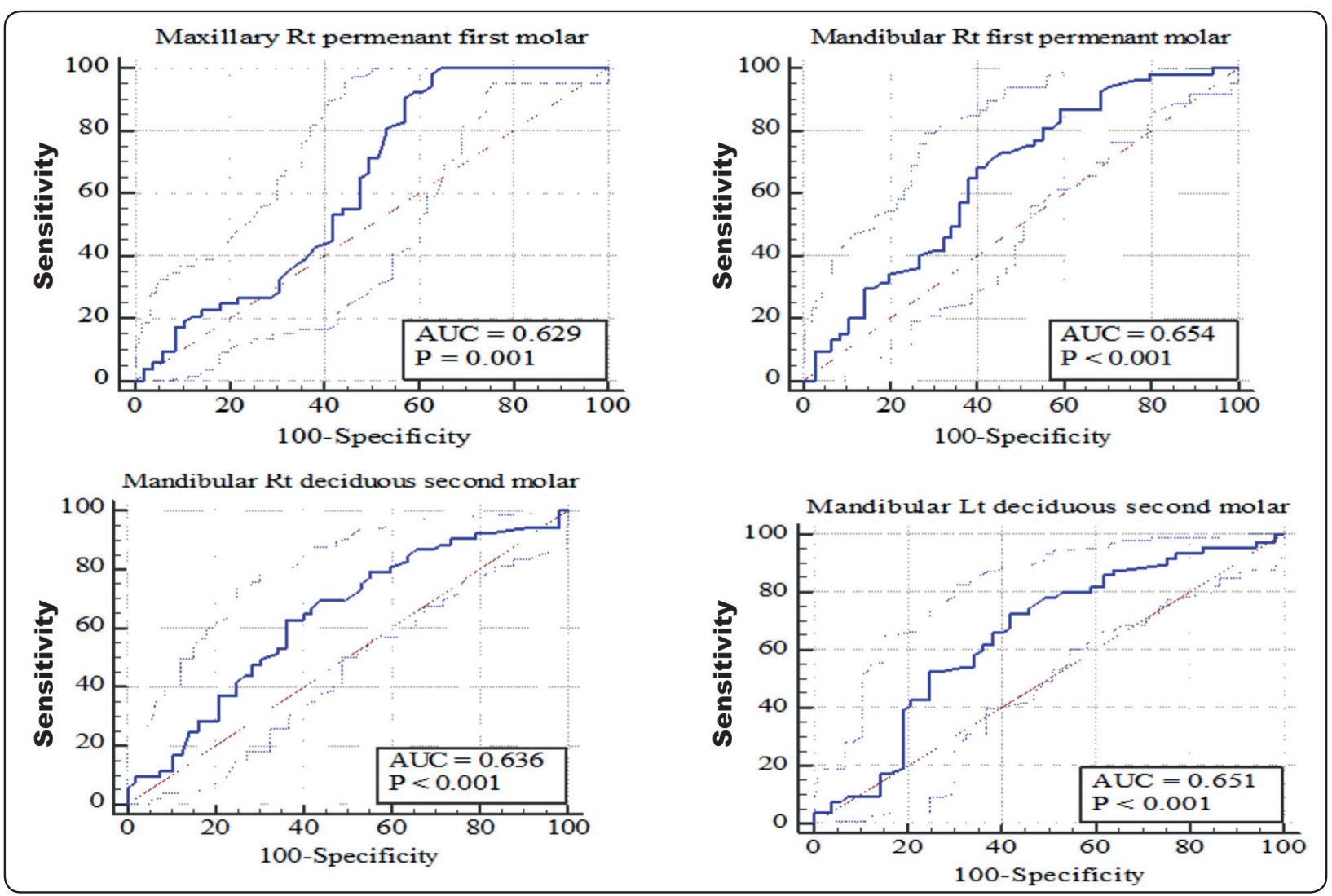

Fig. (2): Receiver operating characteristics (ROC) curve analysis for prediction of male gender.

TABLE (3): Stepwise binary logistic regression analysis for prediction of male gender from the significant studied measures.

\begin{tabular}{|c|c|c|c|c|c|c|c|c|c|c|}
\hline Variables & Coefficient & $\begin{array}{l}\text { Odds } \\
\text { ratio }\end{array}$ & $\begin{array}{l}95 \% \text { CI } \\
\text { of odds }\end{array}$ & $\begin{array}{c}P \\
\text { value }\end{array}$ & $\begin{array}{c}\text { Accuracy } \\
\%\end{array}$ & $\begin{array}{l}\mathbf{R}^{2} \\
\%\end{array}$ & $x_{2}$ & $\begin{array}{c}\mathbf{P} \\
\text { value }\end{array}$ & AUC & $\begin{array}{c}95 \% \text { of } \\
\text { AUC }\end{array}$ \\
\hline $\begin{array}{l}\text { MD diameter of maxillary } \\
\text { Rt permanent first molar } \\
(\mathrm{mm})\end{array}$ & 1.12 & 3.08 & $\begin{array}{c}1.46 \text { to } \\
6.49\end{array}$ & $0.003 *$ & \multirow[t]{3}{*}{69.50} & \multirow[t]{3}{*}{19.20} & \multirow[t]{3}{*}{32.64} & \multirow[t]{3}{*}{$<0.001 *$} & \multirow[t]{3}{*}{0.718} & \multirow[t]{3}{*}{$\begin{array}{c}0.652 \text { to } \\
0.778\end{array}$} \\
\hline $\begin{array}{l}\text { MD diameter of } \\
\text { mandibular Rt permanent } \\
\text { first molar }(\mathbf{m m})\end{array}$ & 0.57 & 1.76 & $\begin{array}{c}1.00 \text { to } \\
3.05\end{array}$ & $0.046^{*}$ & & & & & & \\
\hline $\begin{array}{l}\text { MD diameter of } \\
\text { mandibular Rt deciduous } \\
\text { molar (mm) }\end{array}$ & 0.90 & 2.46 & $\begin{array}{c}1.25 \text { to } \\
4.82\end{array}$ & $0.008^{*}$ & & & & & & \\
\hline
\end{tabular}

*Significant at $p<0.05$ AUC: area under the curve, CI: confidence interval 
Prediction of crown size of mandibular Rt permanent first molar from mandibular $R t$ deciduous second molar:

Simple linear regression revealed the following equations for males and females:

Males: Crown size of mandibular Rt permanent first molar $=14.50-0.35 \mathrm{x}$ mandibular Rt deciduous second molar.

Females: Crown size of mandibular Rt permanent first molar $=2.80+0.82 \mathrm{x}$ mandibular $\mathrm{Rt}$ deciduous second molar.

\section{DISCUSSION}

The present study has the advantage of exploring the accuracy of odontometric analysis of molars in gender determination of Egyptian children in the stage of mixed dentition. Right upper and lower permanent first molars and mandibular deciduous second molars both on the Rt and Lt sides showed sexual dimorphism but, with a low accuracy $(63.5 \%$ to $67.5 \%$ ). Further, new regression equations were presented for prediction of crown size of mandibular Rt permanent first molar from mandibular Rt deciduous second molar.

There was significant sexual dimorphism of the right maxillary and mandibular permanent first molars, with greater means of MD crown diameter in boys than in with girls. Similarly, maxillary casts of Egyptians aged 17-24 years revealed significantly greater median MD dimeter of Rt first molar in males. Alternatively, the Lt side failed to exhibit significant sexual dimorphism ${ }^{(16)}$. Studies in other populations revealed inconsistent results, where significant grades of sexual dimorphism in the Rt first molar dimensions were found $(\mathbf{1 7 , 1 8 , 2 0 )}$ . Asymmetry of the Rt and Lt MD diameters of maxillary first molars has been previously shown ${ }^{(20)}$ .Whereas, Sonika et al., ${ }^{(21)}$ identified greater sexual dimorphism on the Lt than on the Rt maxillary first molars. Nevertheless, symmetrical sexual dimorphism both on the Rt and Lt upper and lower first molars were confirmed ${ }^{(4,5,6,22)}$

Gender determination of juvenile bony remains is a problem that face forensic experts. Investigating sexual dimorphism of crown traits of the deciduous dentition may help to solve this issue ${ }^{(23)}$.

In this study, mandibular deciduous second molars both on the Rt and Lt sides showed significantly larger size in boys than girls. Similarly, studying crown size of deciduous dentition in a sample of European derived Australians revealed significantly higher values in males. Moreover, they reported higher degree of sexual dimorphism in mandibular teeth $(74.8 \%)$ than maxillary ones (55.6\%) Adler and Donlon, ${ }^{(10)}$. Another study investigated Mesiodistal diameter of deciduous teeth in Portuguese explored differences in grades of sexual dimorphism with poor an overall accuracy, ranged from $33.3 \%$ to $75 \%$ Cardoso, ${ }^{(12)}$. Inconsistent with our findings, Shankar et al. ${ }^{(11)}$ reported significant sexual dimorphism of the upper Rt and Lt deciduous molar teeth in a sample of South Indian children aged 5-13 years. Furthermore, studying deciduous first molars using geometric morphometric analysis in Spain showed significant sexual dimorphism in the upper teeth only Lopez-Lazaro et al., ${ }^{(9)}$.

Actually, the observed different forms of sexual dental dimorphism among different populations reflect the effect of genetic and environmental circumstances on teeth development ${ }^{(23)}$.

Greater dental dimensions in males than females could be attributed to greater dentine and enamel thickness in males. Y chromosome induces dentine formation due to increased tooth germ mitosis. Whereas, $\mathrm{X}$ chromosome is known to enhance amelogenesis. Therefore, females, calcification of the crown is completed earlier in both deciduous and permanent dentition ${ }^{(24)}$.

The present study revealed poor accuracy of MD crown diameter of the studied teeth that ranged from $63.5 \%$ to $67.5 \%$. Further, they displayed low 
area under the curve, sensitivity, and specificity. So, they are not considered a good sex predictor. Though, they could be helpful as an auxiliary resource for defining sex. Only Maxillary Rt permanent first molar showed hundred percent sensitivity and negative predictive value, but with a low $(35.24 \%)$ specificity at a cut off more than 9.74 $\mathrm{mm}$. This indicate its greater value in excluding rather than confirming male gender. In agreement with our findings, assessment of permanent teeth accuracy in predicting gender revealed an overall validity (AUC) less than 0.8 in Belgium. Further, a comparable level $(68 \%)$ of sexual dimorphism for deciduous second molar teeth was detected Iranian children Paknahad et al., (25). Whereas, Viciano et al. (26) recorded greater degree of sexual dimorphism in first and second deciduous molars in Spain.

The present study presented regression equations for prediction of crown size of mandibular Rt permanent first molar from mandibular Rt deciduous second molar.

In an attempt to improve the reliability of the measurements undertaken in the present study, all measurements of the mesiodistal diameter of the teeth were performed on stone cast, as they have long been the gold standard for measuring the mesiodistal tooth dimension according to Santoro et al. ${ }^{(27)}$, Quimby et al., ${ }^{(28)}$, Stevens et al., ${ }^{(29)}$ who found that measurements on dental casts were on average of $0.1 \mathrm{~mm}$ greater than those of actual teeth, and measuring of tooth size on both digitalized and stone model revealed 0.16: $0.46 \mathrm{~mm}$ of differences, which were considered clinically not relevant. Furthermore, Anderson ${ }^{(30)}$ used both techniques (direct and indirect) methods of measurement of the teeth in his odontometric study of deciduous dentition, demonstrating that there were no statistically significant differences between the two methods.

In the current study a digital caliper with an accuracy of $0.01 \mathrm{~mm}$ was the instrument used for obtaining measurements instead of the traditional ones. It is considered a reliable method for the assessment of dental crowding even when compared with dedicated software for performing the needed measurement on virtual computerized models ${ }^{(31)}$.

\section{CONCLUSION}

Odontometric study of deciduous and permanent molar teeth showed poor accuracy in sex determination of Egyptian children. They can be used in conjunction with other traits to establish gender accurately. Furthermore, this work presented new equations that will be helpful in estimating crown size of mandibular permanent first molar from mandibular deciduous second molar.

\section{REFERENCES}

1. Forrest, A.J.F.S.R. 2019. Forensic odontology in DVI: current practice and recent advances. Forensic Sciences Research,, 4, 316-330.

2. Dinakaran, J., Dineshkumar, T., Nandhini, G., Priyadharshini, N. \& Rajkumar, K. 2015. Gender determination using dentition. 6, 29-34.

3. Mohsenpour, K., Gangadhar, M. \& Samehsalari, S. J. J. O. M. S. 2017. Mandibular and maxillary canine as a tool for sex determination. Journal of Morphological Sciences, $34,247-250$.

4. Babu, S. S., Nair, S. S., Gopakumar, D., Kurian, N., Parameswar, A. \& BABY, T. K. 2016. Linear Odontometric Analysis of Permanent Dentition as A Forensic Aid: A Retrospective Study. Journal of clinical and diagnostic research : JCDR, 10, ZC24-ZC28.

5. Dash, K. C., Panda, A., Behura, S. S., Ramachandra, S., Bhuyan, 1. \& Bandopadhyay, A. 2018. Employing Dimensional Disparity of Teeth to Establish the Gender in Odisha Population: A Dimorphic Study. J Int Soc Prev Community Dent, 8, 174-178.

6. Shireen, A. \& ARA, S. A. 2016. Odontometric analysis of permanent maxillary first molar in gender determination. Journal of forensic dental sciences, 8, 145-149.

7. Capitaneanu, C., Willems, G., Jacobs, R., Fieuws, S. \& Thevissen, P. 2017. Sex estimation based on tooth measurements using panoramic radiographs. International Journal of Legal Medicine, 131, 813-821. 
8. Zorba, E., Moraitis, K. \& Manolis, S. K. 2011. Sexual dimorphism in permanent teeth of modern Greeks. Forensic Sci Int, 210, 74-81.

9. Lopez-Lazaro, S., Aleman, I., Viciano, J., Irurita, J. \& Botella, M. C. 2018. Sexual dimorphism of the first deciduous molar: A geometric morphometric approach. Forensic Sci Int, 290, 94-102.

10. Adler, C. J. \& Donlon, D. 2010. Sexual dimorphism in deciduous crown traits of a European derived Australian sample. Forensic Sci Int, 199, 29-37.

11. Shankar, S., Anuthama, K., Kruthika, M., Kumar, V. S., Ramesh, K., Jaheerdeen, A. \& Yasin, M. M. 2013. Identifying sexual dimorphism in a paediatric South Indian population using stepwise discriminant function analysis. J Forensic Leg Med, 20, 752-6.

12. Cardoso, H. F. 2010. Testing discriminant functions for sex determination from deciduous teeth. J Forensic Sci, 55, 1557-60.

13. Koora, K., Sriram, C. H., Muthu, M. S., Chandrasekhar Rao, R. \& Sivakumar, N. 2010. Morphological characteristics of primary dentition in children of Chennai and Hyderabad. J Indian Soc Pedod Prev Dent, 28, 60-7.

14. Ashley, M., Mccullagh, A. \& Sweet, C. J. D. U. 2005. Making a good impression:(a'how to'paper on dental alginate). Dental update,, 32, 169-70, 172, 174-5.

15. Gonna, S. A., El-Hosary, A. M. \& Ghobashy, S. A. J. D. J. 2015. Mesiodistal Crown Diameters Of Permanent First Molars And Deciduous Second Molars And Their Relationship To Arch Length Discrepancies. Dental Journal,, 61, 2845.

16. Ali, H. A. A., Radwan, R. A., Hilal, M. J. M. J. O. F. M. \& Toxicology, C. 2019. Prediction of Sex from Teeth Linear Dimensions and Indices. Mansoura Journal of Forensic Medicine and Clinical Toxicology, , 27, 73-86.

17. Patil, S. N., Naik, S. B., Kamble, S. D. \& Kokane, V. B. 2015. To evaluate the accuracy of various dental parameters used for the gender determination in Nagpur District population. Indian J Dent Res, 26, 576-81.

18. Eboh, D. J. J. O. M. S. 2017. A dimorphic study of maxillary first molar crown dimensions of Urhobos in Abraka, South-Southern Nigeria. Journal of Morphological Sciences, 29, 0-0.

19. Mehta, S., Kaur, S., Verma, P., Khosa, R., Sudan, M. \& Kaur, H. 2017. Evaluation of sexual dimorphism using permanent maxillary first molar in Sri Ganganagar population. Indian Journal of Dental Research,, 28, 482-486.
20. AHMED, A. G. 2014. The use of maxillary first molar as forensic aid in racial and sexual dimorphism of Kurdish populaton in Sulaimani city. Sulaimani Dent. J., 1, 1-4.

21. Sonika, V., Harshaminder, K., Madhushankari, G. S. \& Sri Kennath, J. A. 2011. Sexual dimorphism in the permanent maxillary first molar: a study of the Haryana population (India). J Forensic Odontostomatol, 29, 37-43.

22. Agrawal, A., Manjunatha, B. S., Dholia, B. \& Althomali, Y. 2015. Comparison of sexual dimorphism of permanent mandibular canine with mandibular first molar by odontometrics. Journal of forensic dental sciences, 7, 238-243.

23. Dempsey, P. J. \& Townsend, G. C. 2001. Genetic and environmental contributions to variation in human tooth size. Heredity, 86, 685-693.

24. Singla, S., Gupta, R., Puri, A., Bansal, S., Singla, S. \& Nangia, R. 2015. Determination of sexual dimorphism via maxillary first molar teeth in Himachali population. Journal of forensic dental sciences, 7, 90-94.

25. Paknahad, M., Vossoughi, M. \& Ahmadi Zeydabadi, F. 2016. A radio-odontometric analysis of sexual dimorphism in deciduous dentition. J Forensic Leg Med, 44, 54-57.

26. Viciano, J., López-Lázaro, S. \& Alemán, I. 2013. Sex estimation based on deciduous and permanent dentition in a contemporary Spanish population. Am J Phys Anthropol, $152,31-43$

27. Santoro, M., Galkin, S., Teredesai, M., Nicolay, O. F. \& Cangialosi, T. J. 2003. Comparison of measurements made on digital and plaster models. Am J Orthod Dentofacial Orthop, 124, 101-5.

28. Quimby, M. L., Vig, K. W., Rashid, R. G. \& Firestone, A. R. 2004. The accuracy and reliability of measurements made on computer-based digital models. Angle Orthod, 74, 298-303.

29. Stevens, D. R., Flores-Mir, C., Nebbe, B., Raboud, D. W., Heo, G. \& Major, P. W. 2006. Validity, reliability, and reproducibility of plaster vs digital study models: comparison of peer assessment rating and Bolton analysis and their constituent measurements. Am J Orthod Dentofacial Orthop, 129, 794-803.

30. Anderson, A. A. 2005. Dentition and occlusion development in African American children: mesiodistal crown diameters and tooth-size ratios of primary teeth. Pediatr Dent, 27, 121-8.

31. Zilberman, O., Huggare, J. A. \& Parikakis, K. A. 2003. Evaluation of the validity of tooth size and arch width measurements using conventional and three-dimensional virtual orthodontic models. Angle Orthod, 73, 301-6. 